\title{
CONTRIBUIÇÕES DA PERSPECTIVA SÓCIO-HISTÓRICO-CULTURAL PARA PENSAR A APRENDIZAGEM DOS SUJEITOS DA MODALIDADE DE EDUCAÇÃO DE JOVENS E ADULTOS
}

\section{CONTRIBUTIONS OF SOCIAL, HISTORICAL AND CULTURAL PERSPECTIVE TO THINK ABOUT THE LEARNING OF THE SUBJECTS OF YOUTH AND ADULT EDUCATION}

\author{
CONTRIBUCIONES DE LA PERSPECTIVA SOCIO-HISTÓRICA-CULTURAL \\ PARA PENSAR EL APRENDIZAJE DE LOS SUJETOS DE LA EDUCACIÓN PARA \\ JÓVENES Y ADULTOS
}

\begin{abstract}
RESUMO
Um dos grandes desafios da educação brasileira é a garantia de uma aprendizagem de qualidade. No campo da Educação de Jovens e Adultos essa temática aparece, inclusive, nas políticas internacionais como o direito de aprender. A aprendizagem vem recebendo diversos tipos de abordagens especialmente no campo da produção científica da Psicologia e da Pedagogia que, por sua vez, legitimam formas específicas de estruturação dos processos de ensino e aprendizagem e suas metodologias. Neste trabalho, o objetivo é refletir dialeticamente a aprendizagem de pessoas jovens e adultas que constituem a modalidade de Educação de Jovens e Adultos a partir das contribuições da perspectiva sócio-histórico-cultural por meio de revisão bibliográfica dos estudos dos psicólogos soviéticos Vigotski, Luria, Leontiev, do francês Wallon, além de estudiosos que têm desenvolvido suas teorias. A tese central desta reflexão sinaliza para o fato de que a aprendizagem dos sujeitos da EJA não só pode ser qualitativamente desenvolvida como é condição para seu desenvolvimento como pessoas e cidadãos.
\end{abstract}

Palavras-chave: Psicologia social. Pedagogia dialética. Aprendizagem. Educação de Jovens e Adultos.

\begin{abstract}
One of the great challenges to the Brazilian education is to guarantee quality learning. In the field of Youth and Adult Education, this theme appears in the international politics as the right to learning. Learning has been receiving various types of approaches, as observed in the scientific production in the field of Psychology and Pedagogy which, in turn, legitimize specific forms of structuring of teaching and learning processes and their methodologies. In light of this, the objective of this work is to dialectically reflect on the learning of young people and adults that constitute the modality of Youth and Adult Education based on the contributions of the social, historical and cultural perspective. To do so, we have carried out a bibliographic review of the studies of Soviet psychologists such as Vygotsky, Luria, Leontiev, the French psychologist Wallon, and other researchers who have developed their theories. The central thesis of this reflective process points to the fact that the learning of young people and adults can not only be developed with quality but it is a condition for their development as individuals and citizens.
\end{abstract}


Keywords: Social Psychology. Dialectical Pedagogy. Learning. Youth and Adult Education.

\section{RESUMEN}

Uno de los grandes desafíos de la educación brasileña es la garantía del aprendizaje de calidad. En el campo de la Educación de Jóvenes y Adultos, este tema aparece incluso en las políticas internacionales como el derecho a aprender. El aprendizaje ha recibido diversos tipos de enfoques, especialmente en el campo de la producción científica de psicología y pedagogía, que, a su vez, legitiman formas específicas de estructuración de los procesos de enseñanza y aprendizaje y sus metodologías. En este trabajo, el objetivo es reflexionar dialécticamente sobre el aprendizaje de jóvenes y adultos que constituyen la modalidad de Educación Juvenil y de Adultos desde las contribuciones de la perspectiva socio-histórica-cultural a través de una revisión bibliográfica de los estudios de los psicólogos soviéticos Vigotski, Luria, Leontiev, el francés Wallon, y otros eruditos que han desarrollado sus teorías. La tesis central de esta reflexión apunta al hecho de que el aprendizaje de las asignaturas de EJA no solo puede desarrollarse cualitativamente sino que es una condición para su desarrollo como individuos y ciudadanos.

Palabras-clave: Psicología Social. Pedagogía Dialéctica. Aprendizaje. Educación de Jóvenes y Adultos.

Rodrigo de Freitas Amorim

Titulação: Mestre em Educação

Instituição: Instituto Federal de Goiás

E-mail: rodrigo.amorim@ifg.edu.br)

\section{INTRODUÇÃO}

A educação brasileira vivencia diversos problemas que vão desde questões mais amplas, como o financiamento, às situações mais específicas, como a relação professor-aluno no contexto da sala de aula. Tais problemas são visíveis nos baixos índices de aproveitamento escolar, na dificuldade de universalização do ensino médio, nos percentuais de defasagem idade/ano escolar, nas precárias condições de trabalho e salário do corpo docente, entre outros, que certamente têm efeitos diretos sobre o processo de ensino e aprendizagem dos estudantes brasileiros.

A Educação de Jovens e Adultos (EJA), de acordo com o Parecer CNE/CEB n ${ }^{0} 11$, de 10 de maio de 2000, é uma modalidade de ensino da educação básica que perpassa os ensinos fundamental e médio, sendo parte constitutiva dessa estrutura educacional que compartilha de todos os problemas elencados acima. Além desses, essa modalidade apresenta 
dificuldades peculiares às próprias condições para seu funcionamento, tais como o pequeno contingente de matrículas em relação ao quantitativo da população com idade acima de 15 anos que poderia estar matriculada nesta modalidade, o problema de formação do corpo docente que nas licenciaturas do Brasil prioriza o ensino da criança e do adolescente em idade/ano escolar regular e, em muitos cursos, pretere uma formação específica para pensar as pessoas jovens, adultos e idosos que constituem a EJA. Isso, sem mencionar o problema histórico do modus operandi do ensino supletivo que foi herdado pela EJA como um tipo de ensino aligeirado e de baixa qualidade para resolver o problema de certificação daqueles que não puderam acessar ou permanecer na escola na idade própria.

Diante desse amplo cenário, este ensaio tem como objetivo refletir especificamente sobre o problema da aprendizagem das pessoas jovens e adultas que constituem os sujeitos educandos da modalidade de EJA. Guiam nossa reflexão as seguintes questões: Como essas pessoas, que não conseguiram acessar a escola e/ou permanecer nela numa idade própria, aprendem? Há diferença na sua forma de aprender em relação à infância e adolescência? Que perspectivas de aprendizagem do campo teórico da Psicologia e Pedagogia propiciam explicações e concepções que se adequem de modo mais criterioso e eficaz à aprendizagem desses sujeitos?

Para responder a essas questões, ainda que de forma embrionária, tomaremos como referencial teórico os estudos da perspectiva sócio-histórico-cultural baseados no pensamento dos psicólogos soviéticos Vigotski, Luria e Leontiev, bem como o francês Wallon. Esses autores realizaram estudos empíricos numa perspectiva crítica em relação à Psicologia de sua época, a qual defendia premissas epistemológicas positivistas e burguesas, dissociando sua compreensão do ser humano da realidade histórica e social, com vistas a um "indivíduo" cujas características psicológicas poderiam ser investigadas e compreendidas a par de suas relações sociais com a sociedade mais ampla. Essa Psicologia tradicional ofereceu as bases teóricas fundamentais para a Pedagogia burguesa que emergiu no século XIX nos países de produção capitalista, oferecendo modelos de aprendizagem e explicações sobre o comportamento humano e suas funções psíquicas superiores, resultando em concepções pedagógicas de aprendizagem intimamente ligadas à ideia de um "etapismo" biológico do desenvolvimento humano como condição inexorável para os processos de ensino e aprendizagem. Assim, especialmente a infância foi escolhida como o momento "ideal" da aprendizagem humana condicionada às etapas do desenvolvimento biológico do indivíduo. 
Diante desse contexto, os teóricos da perspectiva sócio-histórico-cultural, convencidos de uma visão crítica da realidade a partir das contribuições do materialismo histórico dialético de Marx e Engels, aplicaram ao campo da Psicologia e da Pedagogia os princípios dessa emergente visão de mundo e de produção do conhecimento científico. Como resultado às críticas feitas às correntes tradicionais e aos estudos realizados a partir de outras bases epistemológicas, esses teóricos fizeram novas descobertas científicas e proposições quanto ao campo do psiquismo humano demonstrando também novas concepções para a aprendizagem. $\mathrm{O}$ entendimento de que a história social do ser humano é fundamental na formação do seu psiquismo e das funções psicológicas superiores demarcou um novo axioma com desdobramentos para o campo pedagógico.

Por esse motivo, nos propusemos fazer uma reflexão teórica baseada na produção bibliográfica desses autores e de outros pesquisadores que vêm utilizando seu pensamento como premissa teórica para suas pesquisas, com o objetivo de encontrar elementos que nos ajudem a pensar a aprendizagem dos sujeitos da EJA. Trata-se, portanto, de um exercício de reflexão para encontrar implicações teórico-práticas que contribuam com o trabalho do(a) professor(a) da EJA no enfrentamento das dificuldades de aprendizagem de seus educandos e educandas.

\section{A APRENDIZAGEM NA PERSPECTIVA DA PSICOLOGIA E PEDAGogia TRADICIONAIS}

Barbosa (1991) analisa as correntes psicológicas e pedagógicas mais importantes para pensarmos os processos de ensino e aprendizagem. Para a autora, são classificadas como

Psicologia e Pedagogia tradicionais as correntes empiristas/sensualistas e católicas/neotomistas, que, apesar de apresentarem diferenças e divergências entre si sobre as concepções da natureza humana, mundo, sociedade e aprendizagem, têm em comum o fato de que, em grande medida, elas atendem aos ideais liberais e burgueses da sociedade, além de não verem o trabalho como força motriz capaz de constituir a história social da humanidade. Outro aspecto em comum dessas correntes, é o fato de que o ser humano e sua educação são enfatizados em estudos de viés individualista a parte da influência que o meio social exerce sobre sua formação. Por fim, privilegiam a infância como momento "certo" para efetivar a educação, não tomando a educação do adulto e sua aprendizagem como objeto de análise, 
pois que depois da infância os estágios e etapas de desenvolvimento humano já teriam sido consolidados. Desta forma, jovens e adultos que não acessaram ou não permaneceram na escola na idade da infância para conciliar a aprendizagem escolar com as etapas "naturais" de seu desenvolvimento biológico, teriam "perdido" o tempo ideal para realizá-la. Nesta perspectiva, a aprendizagem humana é delimitada à infância, momento da vida humana em que a criança processa "naturalmente" os estágios de seu desenvolvimento.

Historicamente, os problemas da educação e da aprendizagem do adulto nunca foram de interesse social relevante para a sociedade burguesa. Por que essa indiferença? Ao estudar as diversas correntes das psicologias e pedagogias liberais e burguesas percebemos que: a) essas psicologias focalizaram a aprendizagem da criança como ser que está no momento "ideal" do processo de aprender, disso decorrendo uma consequência lógica: o adulto já teria passado da etapa proeminente da aprendizagem; b) as escolas foram pensadas inicialmente para atender as crianças e, o próprio surgimento da pedagogia como um conjunto de saberes sobre os processos de ensino e aprendizagem estão, como o nome já diz, voltados para a criança; c) aos adultos, na sociedade burguesa, resta-lhes o mundo do trabalho como meio de sobrevivência, portanto, não é pensada uma escola para esse grupo, exceto numa perspectiva dualista em que aos ricos é garantido o acesso à Universidade e aos trabalhadores pobres são destinados os cursos profissionalizantes para treinamento e capacitação de mão de obra para atender às novas demandas sociais do trabalho produtivo no contexto do sistema de produção capitalista. Dados esses fatores, não é de se admirar que o adulto não tenha sido exclusivamente um interesse de objeto de estudo em relação à sua capacidade de aprendizagem, ${ }^{1}$ especialmente o adulto trabalhador das classes menos favorecidas.

No que diz respeito à realidade brasileira, as campanhas de combate ao analfabetismo iniciadas a partir dos anos de 1947 (PAIVA, 2003), ignoravam as características próprias da aprendizagem das pessoas adolescentes, jovens e adultos analfabetas e utilizavam materiais didáticos - as cartilhas - com linguagem totalmente

\footnotetext{
${ }^{1}$ É importante lembrar aqui a tese do professor Paschoal Lemme (1904-1997) em que trata dos fundamentos psicológicos da educação de adultos, ainda na década de 1930, pois demonstra como estudos empreendidos nos Estados Unidos por Thorndike sobre a aprendizagem de adultos, ainda que tenham sido feitos numa perspectiva tradicional, revelaram empiricamente que adultos entre 25 e 45 anos de idade tinham as mesmas capacidades de aprendizagem de crianças e adolescentes em contexto escolar. É interessante destacar que Paschoal Lemme estava combatendo uma ideia culturalmente disseminada de que somente a infância era o momento "certo" para a aprendizagem. Também, podemos supor que naquela época, Lemme não teve acesso aos estudos da psicologia e pedagogia soviética. (Cf. LEMME, 2004, p. 59-64)
} 
infantilizada. $^{2}$ Esse fato demonstra quão indiferentes eram as políticas públicas e seus atores políticos quanto à questão da aprendizagem do adulto, bem como reforça nossa tese de que havia, por detrás dessas decisões governamentais pressupostos advindos das correntes tradicionais do campo da Psicologia e Pedagogia que ratificavam tais medidas.

Uma das críticas mais veementes dos teóricos soviéticos à Psicologia tradicional era direcionada à relação desenvolvimento e aprendizagem. De acordo com Vigotski, Luria e Leontiev, a aprendizagem no contexto da Psicologia tradicional era consequência do processo de desenvolvimento humano baseado nas etapas biológicas naturais de seu amadurecimento. Desse modo, seria preciso que dentro de cada estágio do desenvolvimento se consolidasse determinados amadurecimentos biológicos sem os quais era impossível a aprendizagem. Sem desenvolvimento não haveria aprendizagem. Piaget, por exemplo, denominou esses estágios de desenvolvimento em: sensório motor, pré-operatório, operatório concreto e operatório formal, estabelecendo assim uma série de estágios lineares de desenvolvimento humano, de modo que para cada estágio do desenvolvimento caberia um tipo específico de aprendizagem.

Chegada à fase adulta, em que já não mais se observa a continuidade de estágios de desenvolvimento, a aprendizagem ficaria restrita ao que já se obteve no passado. Qual é a consequência lógica desse tipo de raciocínio para o público da EJA que perdeu o estágio “ideal” para aprender, que era a infância? Obviamente, um déficit em sua capacidade de aprendizagem. Ou seja, é possível afirmar que, de certo modo, essas concepções psicológicas tradicionais serviram de suporte para uma série de ideias estereotipadas sobre a aprendizagem do adulto não escolarizado, tais como "ele não é capaz de aprender", “já passou da idade”, “este conteúdo é difícil demais", "ele não desenvolveu a capacidade de abstrair, agora já é

\footnotetext{
${ }^{2}$ No portal dos Fóruns de Educação de Jovens e Adultos (www.forumeja.org.br/educacaopopular), há dados da pesquisa do Prof. Dr. Osmar Fávero sobre as campanhas de educação de alfabetização de adolescentes e adultos entre os anos de 1947 e 1964 que trazem os modelos das cartilhas de alfabetização utilizadas naquela época. Algumas cartilhas apresentavam o palhaço e um texto infantil para promover a alfabetização das pessoas adultas. Paiva (2003) destaca que no II Congresso Nacional de Educação de Adolescentes e Adultos, de 1958, esse foi um dos temas criticados pelos congressistas - a infantilização da linguagem das cartilhas.

${ }^{3}$ De acordo com a Prof. ${ }^{a}$ Dr. ${ }^{\text {a }}$ Ivone Garcia Barbosa, na aula do dia 25 de abril de 2018, do PPGE-FE/UFG, Piaget, quando provocado e questionado por pesquisadores espanhóis, teria admitido erro na determinação da idade do estágio operatório motor, sugerindo que este não se daria entre os 11 e 12 anos, mas entre os 14 e 15 anos de idade. Isso demonstra como tal "erro" prejudicou uma variada gama de reformas educacionais, inclusive no Brasil dos anos de 1990, quando foi editado os Parâmetros Curriculares Nacionais baseados na teoria piagetiana. Ou seja, a individualização do processo de aprendizagem em detrimento das questões sociais dos sujeitos acaba por justificar os problemas do fracasso escolar, isentando, inclusive os erros teóricos dos pesquisadores.
} 
tarde demais para isso", entre outros discursos que povoam o imaginário coletivo tanto de professores(as) quanto dos próprios sujeitos educandos e educandas da EJA.

Sob essa perspectiva, portanto, a aprendizagem é compreendida como uma capacidade humana individual determinada diretamente pelas etapas do desenvolvimento biológico nas quais haveria momentos "ideais" - principalmente a infância - para se aprender. Transcorridas as etapas biológicas do desenvolvimento humano sem o adequado aproveitamento da aprendizagem, a consequência lógica seria uma perda na capacidade de aprendizagem na fase adulta, justificando assim os estereótipos acima e determinada inércia para a transformação do modelo de ensino de pessoas jovens e adultas.

\section{A APRENDIZAGEM NA PERSPECTIVA DA PSICOLOGIA E PEDAGOGIA SÓCIO-HISTÓRICO-CULTURAIS}

Os pesquisadores da corrente psicológica da perspectiva sócio-histórico-cultural, fundadas no materialismo histórico-dialético, tais como Vigotski, Leontiev, Luria e Wallon, focalizaram diretamente o fenômeno da aprendizagem não tanto a questão da aprendizagem do adulto. Em termos de verificação empírica, realizaram diversas experiências com crianças além de analisarem dados empíricos de outras experiências com a infância feitas pelas correntes tradicionais (VIGOTSKI, 2007, 2008, 2010). Isso não significa que suas teorias não tenham aplicação direta com o problema da aprendizagem do adulto, pelo contrário, a forma como conceberam a aprendizagem e sua relação com o desenvolvimento do psiquismo humano permite-nos compreender a aprendizagem como um fenômeno da vida humana em todas as suas fases, da tenra infância à velhice.

Wallon (1975), por exemplo, em seus estudos sobre o que constitui o psiquismo humano, essa capacidade biopsicológica que distingue o ser humano das demais espécies, verificou que o desenvolvimento biológico se associa ao meio ambiente de forma complexa e única na espécie humana. Esse autor criticava as teorias de Piaget, porque conforme suas palavras:

Para alguns psicólogos [Piaget e sua escola], seria suficiente comprovar as diferenças qualitativas do conteúdo mental de cada idade, como se este conteúdo obedecesse mais a uma lógica interna e universal que às influências do meio. Para estes, a ação do meio seria puramente abstrata. A passagem do pensamento infantil para o adulto seria uma transição gradual de um pensamento absolutamente 
individual e voltado exclusivamente para si mesmo para um pensamento que, ao se socializar, aprenderia a limitar suas concepções na medida em que fosse percebendo que elas são inconciliáveis com os pontos de vista do outro, obrigando-se a não utilizar a não ser aqueles que o pensamento do outro pudesse usar ao mesmo tempo. É a tese do "Contrato Social" transposta para a psicologia. (WALLON, 1971, p. 252-253)

Em outras palavras, essas psicologias ignoravam a relação do desenvolvimento do psiquismo humano com o meio social, delegando de forma absoluta ao fator biológico as condições de desenvolvimento das capacidades psíquicas dos seres humanos.

É interessante como Wallon concilia essa teoria aos postulados filosóficos, ideológicos e burgueses do "Contrato Social" defendidos pela Revolução Francesa. Assim, em seus estudos, o autor demonstra que "não é apenas a complexidade da estrutura que está em causa. É o tipo de relações que o organismo tem com o meio que manterá as suas relações ao nível de mecanismos fisiológicos ou que os fará passar ao psiquismo.” (WALLON, 1975, p. 54)

Dentro dessa proposta, a psicogênese no homem está relacionada aos fatores biológicos e ao meio em que está inserido. Apesar de todos os elementos biológicos com que nascem os seres humanos, nada se pode por meio deles sem a intervenção do meio. "A psicogênese não é, portanto, automática, não tem uma progressão necessária. A maturação do sistema nervoso, que torna sucessivamente possíveis diferentes tipos ou diferentes níveis de atividade, é preciso que se junte o exercício que deve ser tão diverso quanto possível.” (WALLON, 1975, p. 60). Esse exercício é proposto contínua e ininterruptamente de maneira formal ou informal pelo meio social em que está inserido o ser humano desde suas primeiras vivências.

Para Leontiev (1978), no processo de desenvolvimento evolutivo do ser humano se constituíram leis sócio-históricas que suplantaram as leis biológicas, de modo que o homem atual apresenta "todas as propriedades biológicas necessárias ao seu desenvolvimento sócio-histórico ilimitado.” (p. 263). Compreende-se que essas leis sócio-históricas constituem os fatores determinantes da vida humana, sem que se negue a existência dos fatores biológicos. São as leis sócio-históricas que constituem o processo de hominização do ser humano que cria uma história social. Essa história social pode ser compreendida pelo fato de que 
Cada geração começa, portanto, a sua vida num mundo de objetos e de fenômenos criado pelas gerações precedentes. Ela apropria-se das riquezas deste mundo participando no trabalho, na produção e nas diversas formas de atividade social e desenvolvendo assim aptidões especificamente humanas que se cristalizaram, encarnaram nesse mundo. (LEONTIEV, 1978, p. 265-266)

Isso ocorre de modo que o indivíduo se constitui humano não pelo fator biológico hereditário que veio a receber da natureza, mas pela capacidade de aprender e adquirir o que foi alcançado pela sociedade em sua história social. "Podemos dizer que cada indivíduo aprende a ser um homem. O que a natureza lhe dá quando nasce não lhe basta para viver em sociedade. É-lhe ainda preciso adquirir o que foi alcançado no decurso do desenvolvimento histórico da sociedade humana.” (LEONTIEV, 1978, p. 267, grifo do autor)

Se o indivíduo aprende a ser homem, e o aprende em sociedade, na coletividade, então, a transmissão dos conhecimentos e instrumentos das gerações antecessoras às atuais e futuras é fundamental para o seu permanente desenvolvimento. Esse processo é realizado pela educação, de modo que para Leontiev $(1978$, p. 273) a relação entre o progresso histórico e o progresso da educação "é tão estreita que se pode sem risco de errar julgar o nível geral do desenvolvimento histórico da sociedade pelo nível de desenvolvimento do seu sistema educativo e inversamente." Em outras palavras, o investimento social em educação de uma dada sociedade seria diretamente proporcional ao seu desenvolvimento histórico social.

Disso decorre uma implicação interessante da teoria de Leontiev sobre as desigualdades entre os indivíduos dentro de sua coletividade como humanidade. Ele questiona: todos têm acesso às aquisições desenvolvidas pelas gerações precedentes? Não! Comparando animais e homens, afirma que a unicidade da espécie animal que pode ser facilmente reconhecida pelo estudo de um único indivíduo de um determinado grupo animal não se confirma no ser humano. Isso é diferente. Um único homem não oferece a visão total da espécie porque ela está marcada por um desenvolvimento desigual na sua evolução sócio-histórica, são desigualdades econômicas, de classes etc. e a diferenciação na aquisição diferencia também o desenvolvimento humano. Não se trata de fatores biológicos, mas sócio-históricos. Trata-se da separação entre desenvolvimento biológico e desenvolvimento sócio-histórico. Essa separação é que possibilita o fato de o ser humano se diferenciar de seus pares em outros elementos, dentre eles, o principal, o fator econômico. (LEONTIEV, 1978)

Isso explicaria, portanto, a diferença nos processos de aprendizagens entre pessoas jovens e adultas não escolarizadas daqueles que se escolarizaram. Se tomarmos um indivíduo 
que desde sua tenra idade teve acesso qualitativo aos bens culturais da humanidade como a escola, a arte, o teatro, a música, entre outros, e o comparamos com outro que não acessou esses bens, certamente na fase adulta apresentar-se-ão diferenças significativas em seu grau de desenvolvimento humano, diferentes capacidades de aprendizagem. Poder-se-á dizer que um é mais "inteligente" que o outro; que o primeiro é mais capaz que o outro. Observe-se que a explicação biologicista buscaria a causa dos problemas da aprendizagem no indivíduo, enquanto a explicação sócio-histórico-cultural entende que essa causa é eminentemente social.

Enfim, quando Leontiev (1978) destaca a importância da cultura para o desenvolvimento do psiquismo humano e frisa a educação e os processos de transmissão de conhecimento que se dão por meio dela como fatores decisivos, podemos dizer que ele está demonstrando que a aprendizagem, ainda que se materialize no indivíduo, ela é um fenômeno social que recebe influência de todos os fatores que constituem a sociedade em sua coletividade, fatores sociais, culturais, políticos e econômicos, em especial.

Luria (1991) defendeu a Psicologia sócio-histórico-cultural como um campo científico de métodos próprios que se contrapõe às psicologias tradicionais visto que não conseguiram avançar na superação das concepções dualistas e mecanicistas do ser humano. Um tema importante em suas pesquisas é a atividade consciente do homem e sua relação com o meio social e histórico.

Para esse autor, a atividade consciente do homem é diferente da atividade dos animais. Três fatores são determinantes dessa diferença: a) a atividade consciente do homem não está “obrigatoriamente ligada a motivos biológicos" (LURIA, 1991, p. 71), mas está baseada em complexas necessidades "superiores" ou "intelectuais"; b) a atividade consciente do homem não é exclusivamente determinada pelas influências exteriores do meio em que está, ele supera as influências da "experiência individual imediata", pois se guia por um conhecimento mais amplo da realidade que obteve historicamente (LURIA, 1991, p. 72); c) o fato de o comportamento humano ter a capacidade de aprender conhecimentos e habilidades advindos de toda a humanidade e não ser apenas um ser determinado por fatores hereditários e de experiências individuais, como os animais. Desde o seu nascimento, o aprendizado humano é marcado pela história social das coisas que a criança tem contato. Para o autor,

A grande maioria de conhecimentos, habilidades e procedimentos do comportamento de que dispõe o homem não são o resultado de sua experiência 
própria mas adquiridos pela assimilação da experiência histórico-social de gerações. Este traço diferencia radicalmente a atividade consciente do homem do comportamento do animal. (LURIA, 1991, p. 73)

É importante destacarmos aqui que as raízes históricas e sociais que constituem a atividade consciente do homem não são concebidas de forma mecânica, como se o simples contato com o mundo exterior constituísse automaticamente os processos psíquicos superiores do ser humano. Há um processo dialético entre a relação do indivíduo com o meio exterior, de maneira que o meio exterior - que também é objetivação das subjetividades - à medida que coopera com o desenvolvimento do indivíduo em sua consciência vai se constituindo interior neste, ou seja, consciência interior no sujeito. Essas múltiplas e complexas relações não são apenas relações de troca entre o sujeito e o objeto, mas relações simbióticas de um campo mais amplo - social, histórico e cultural - em que o sujeito se constitui pelo objeto e o objeto se constitui pelo sujeito. Não haveria nem um nem outro sem que ambos constituíssem a própria realidade histórica.

Por conseguinte, Luria (1991) destaca que essas relações múltiplas, complexas e dialéticas que constituem a consciência humana são objetivadas por três instrumentos básicos: o trabalho social, o emprego dos instrumentos de trabalho e a linguagem. Esses três instrumentos deram as condições objetivas para o desenvolvimento da consciência humana que “não devem ser procuradas nas peculiaridades da 'alma' nem no íntimo do organismo humano mas nas condições sociais da vida historicamente formadas." (p. 75, grifos do autor). Para Luria (1991), portanto, "a grande maioria dos conhecimentos e habilidades do homem se forma por meio da assimilação da experiência de toda a humanidade, acumulada no processo da história social e transmissível no processo de aprendizagem.” (p. 73, grifos do autor). Há uma contínua relação dialética fundamental em face da história social herdada e dos processos de aprendizagem que constituem a consciência humana.

Quanto a Vigotski, o deixamos por último porque ele é o grande estudioso da psicologia e pedagogia soviética cujas pesquisas e teorias serviram de base para seus colegas Luria e Leontiev darem prosseguimento aos seus estudos, bem como Wallon, na França. Morreu em 1934, aos 38 anos, sem ter tido tempo de continuar aprofundando todos os seus estudos (IVIC, 2010). Isso, no entanto, não impediu que essa nova psicologia tivesse continuidade e desdobramentos, a partir de seus postulados que abordaram as questões relativas à sociabilidade humana, à interação social, aos signos e instrumentos, à cultura, à 
história e às funções mentais superiores, as quais se poderiam designar de teoria sócio-histórico-cultural do desenvolvimento das funções mentais superiores. (IVIC, 2010)

Como teórico de vanguarda, Vigotski demonstrou como o meio em interação com o ser humano propicia seu desenvolvimento psíquico e sua personalidade. Observe sua compreensão sobre o meio, em suas palavras:

\begin{abstract}
Chegamos à conclusão de que o meio não pode ser analisado por nós como uma condição estática e exterior com relação ao desenvolvimento, mas deve ser compreendido como variável e dinâmico. Então o meio, a situação de alguma forma influencia a criança, norteia o seu desenvolvimento. Mas a criança e seu desenvolvimento se modificam, tornam-se outros. E não apenas a criança se modifica, modifica-se também a atitude do meio para com ela, e esse mesmo meio começa a influenciar a mesma criança de uma nova maneira. Esse é um entender dinâmico e relativo do meio - é o que de mais importante se deve extrair quando se fala sobre o meio na pedologia. (VIGOTSKI, 2010, p. 691)
\end{abstract}

Através da vivência humana com esse meio variável e dinâmico se constituem os condicionamentos múltiplos e complexos que promovem o desenvolvimento. Acrescenta que "[...] na vivência, nós sempre lidamos com a união indivisível das particularidades da personalidade e das particularidades da situação representada na vivência." (VIGOTSKI, 2010, p. 686) No bojo dessa interação social está a aprendizagem, entendida como elemento propulsor do desenvolvimento.

Diferentemente da psicologia genética de Piaget, que condiciona a aprendizagem ao desenvolvimento biológico, Vigotski inverteu os polos e demonstrou como, na verdade, o desenvolvimento é resultante do processo de aprendizagem, conforme (Figura 1) abaixo:

Figura 1 - A relação desenvolvimento e aprendizagem

CONCEPÇÃO PIAGETIANA - FATOR BIOLÓGICO DETERMINANTE

DESENVOLVIMENTO $\rightarrow$ APRENDIZAGEM

CONCEPÇÃO VYGOTSKYANA - FATOR SOCIAL DETERMINANTE

APRENDIZAGEM $\rightarrow$ DESENVOLVIMENTO

Fonte: (próprio autor)

Um dos principais temas ilustrativos dessa nova forma de conceber a relação entre desenvolvimento e aprendizagem está nos estudos da linguagem. Com o exemplo da fala, 
comparando a fala final - ideal - aquela que se espera obter ao final do desenvolvimento, com a fala primária - inicial - aquela que se vai processando no início de seu desenvolvimento, Vigotski (2010, p. 693) demonstrou como "há algo, algo que deve se construir bem ao final do desenvolvimento, e que, de alguma maneira, influencia logo o início desse desenvolvimento.” Ou seja, já no início do desenvolvimento da fala da criança, ainda muito distante de seu ideal, a fala ideal já está integralmente presente no seu meio de vivência como condição histórica e social indispensável ao seu desenvolvimento.

Vigotski afirma que essa forma de influência do meio sob a relação de uma forma final com uma forma inicial é uma particularidade do mundo infantil, e que não há correlações em outros aspectos da realidade, nem da evolução biológica, nem da história da organização da sociedade, nem da economia. No caso específico da criança, o meio desempenha o papel de "fonte de desenvolvimento", não se trata apenas de uma circunstância, mas de uma "fonte". O que isso implica? Que se a criança for privada em seu meio de desenvolvimento de uma forma final ou ideal, ela não alcançará tal desenvolvimento até o fim. Ainda para o autor,

Então, nesse sentido, deve-se considerar em primeiro lugar que o meio consiste em fonte de todas as propriedades humanas específicas da criança - se não há no meio uma forma ideal correspondente, então, na criança, não se desenvolverá a ação, a propriedade correspondente, a qualidade correspondente. (VIGOTSKI, 2010, p. 695)

Em segundo lugar, havendo o relacionamento de crianças num meio em que outras crianças também estão expostas a ambientes sem aquela forma final ou ideal, o desenvolvimento se processará de forma muito lenta e nunca alcançará a forma ideal.

É possível verificar nesse ponto da teoria de Vigotski uma explicação do porquê pessoas jovens e adultas que foram privadas do acesso e/ou permanência à escola na infância apresentam tantas dificuldades de aprendizagem quando retornam às salas de aula. A ausência do espaço escolar como forma ideal de transmissão e assimilação de conhecimentos teria afetado o desenvolvimento final que a vivência nesse meio poderia ter propiciado. Isso não significa que essas pessoas não aprendam ou que não tenham se desenvolvido como sujeitos sociais, ao contrário, elas geralmente se inserem cedo no mundo do trabalho e em uma rede de relações sociais outras (fora da escola) em que diversos saberes sensíveis e empíricos vão se 
constituindo, porém o retorno à escola não deixa de ser sempre um grande desafio. Em acréscimo,

[...] o meio desempenha, com relação ao desenvolvimento das propriedades especificas superiores do homem e das formas de ação, o papel de fonte de desenvolvimento, ou seja, a interação com o meio é justamente a fonte a partir da qual essas propriedades surgem na criança. E se essa interação com o meio for rompida, só por força das inclinações encerradas na criança as propriedades correspondentes nunca surgirão por conta própria. (VIGOTSKI, 2010, p. 697, grifos do autor)

Isso ratifica o poder do meio sobre o desenvolvimento humano, poder não só de influência, mas sobretudo de fonte desse desenvolvimento. Portanto, a capacidade de aprender que se vincula à interação social dos sujeitos com outros em seu meio, desde tenra infância, é o que vai promovendo o desenvolvimento das funções mentais superiores.

De acordo com Ivic (2010), no plano pedagógico, a relação entre desenvolvimento e aprendizagem em Vigotski se desenvolveu na noção de "zona de desenvolvimento proximal", que se compreende como "a diferença (expressa em unidades de tempo) entre os desempenhos da criança por si própria e os desempenhos da mesma criança trabalhando em colaboração e com a assistência de um adulto.” (p. 32) Essa noção apresenta implicações pedagógicas de grandes significados para se pensar os processos de aprendizagem no contexto escolar. Ainda segundo Ivic (2010, p. 32-33):

\footnotetext{
Aplicada à pedagogia, essa noção permite sair do eterno dilema da educação: é necessário esperar que a criança atinja um nível de desenvolvimento particular para começar a educação escolar, ou é necessário submetê-la a uma determinada educação para que ela atinja tal nível de desenvolvimento? Na linha das ideias dialéticas das relações entre processos de aprendizagem e de desenvolvimento que analisamos, Vigotski acrescenta que este último é mais produtivo se a criança é exposta a aprendizagens novas, justamente na zona de desenvolvimento proximal. Nessa zona, e em colaboração com o adulto, a criança poderá facilmente adquirir o que não seria capaz de fazer se fosse deixada a si mesma.
}

Apesar do extensivo trabalho teórico e empírico de Vigotski sobre o desenvolvimento humano a partir da infância, há que se destacar que suas pesquisas estão pensando o ser humano como um todo. Pensar a infância é ponto de partida do adulto para compreender-se a si próprio e não para estandartizar estágios ou fases que pertençam exclusivamente à criança. Com isso, podemos afirmar que há muitos elementos na teoria de Vigotski e demais psicólogos soviéticos que nos ajudam a pensar a aprendizagem de pessoas jovens e adultas da modalidade de EJA. É o que pretendemos destacar na seção a seguir. 


\section{CONTRIBUIÇÕES PARA PENSAR A APRENDIZAGEM DE PESSOAS JOVENS E ADULTAS DA EJA}

A primeira grande contribuição da perspectiva sócio-histórico-cultural para pensar a aprendizagem de pessoas jovens e adultas da EJA é a desmistificação do dualismo homem-matéria, subjetivo-objetivo, criança-adulto. Essas dicotomias presentes nas correntes empiristas/sensualistas e católicas/neotomistas das psicologias e suas consequentes pedagogias legitimaram concepções de desenvolvimento humano inatistas e/ou empiristas dissociadas de seu meio social, legando, consequentemente, ao indivíduo em si o mérito do sucesso ou do fracasso em sua aprendizagem dos conhecimentos da humanidade. Neutralizou-se o meio social com suas implicações políticas, culturais e econômicas como se esses fatores em nada interferissem nas condições de desenvolvimento e aprendizagem humanas. A compreensão dessas concepções dicotômicas só foi possível com o surgimento de uma visão psicológica materialista e dialética da história, pois denunciou o viés ideológico dessas concepções e demonstrou como o desenvolvimento e a aprendizagem humanos se dão dialeticamente na relação do homem com o mundo, com os outros homens (as gerações antecessoras e atuais) e com seus instrumentos sociais de trabalho. Desse modo, elimina-se a culpa do indivíduo adulto não escolarizado pelo seu fracasso escolar e se percebe que em condições materiais e sociais concretas esse sujeito é tão apto para aprender quanto qualquer outro ao qual tenha sido garantido tais condições.

A segunda grande contribuição é o fato de que a perspectiva sócio-histórica-dialética desmistifica a ideia advinda das psicologias e pedagogias tradicionais de que a infância é a etapa ideal para os processos de aprendizagem e que, na fase adulta, aqueles que não desenvolveram suas capacidades de aprendizagem quando crianças não teriam mais as mesmas condições de aprendizagem. Disso decorrem dois graves problemas: o primeiro que associa aprendizagem e infância e, o segundo, que antagoniza aprendizagem e vida adulta. Entretanto, tais concepções foram desmistificadas pelas teorias histórico-culturais, uma vez que demonstraram ser a aprendizagem um fenômeno para toda a vida. Exemplo disso é a afirmação do pedagogo soviético Savin (apud BARBOSA, 1991, p. 119) sobre o desenvolvimento da personalidade humana: 
A personalidade resultaria, então, dos processos de desenvolvimento físico-psíquico e de educação, chamados no seu conjunto de "processo formação" o qual ocorreria ao largo de toda a vida. Considerou, portanto, a personalidade como um fenômeno complexo, mutável e que se desenvolveria de acordo com a sociedade no processo de atividade social e do trabalho.

Isso demonstra que a perspectiva sócio-histórico-cultural da educação tem uma concepção de constituição humana e de seus percursos formativos como algo dinâmico que pode se desenvolver durante toda a vida, dependendo, contudo, das condições sociais e materiais concretas e objetivas em que o ser humano é sujeitado durante toda a sua vida. Se, da infância à velhice, são disponibilizadas ao ser humano condições de acesso e continuidade ao conhecimento escolar, científico, social, político e cultural, esse tenderá a desenvolver sua personalidade também continuamente. Se lhe é negado o acesso aos bens culturais da humanidade e suas condições de existência permanecem ao nível da mera luta pela sobrevivência, não se pode esperar um nível de desenvolvimento conciliável com as exigências da civilização moderna contemporânea.

Uma terceira grande contribuição é a compreensão da importância da transmissão e assimilação dos conhecimentos como parte dos processos de aprendizagem e desenvolvimento humanos. Nesse sentido, podemos pensar uma implicação teórica e prática para a aprendizagem de pessoas jovens e adultas da EJA. Na Psicologia genética de Piaget, o construtivismo se desenvolveu como teoria da aprendizagem em que o sujeito aprende quando em contato com o meio externo tem seus esquemas mentais modificados internamente. A experiência com o meio seria fundamental para a construção do conhecimento. Obviamente que essa relação com o objeto deve se dar a partir de métodos e conteúdos adequados a cada estágio do desenvolvimento. Nessa perspectiva, negam-se os processos de transmissão e assimilação de conhecimentos como válidos para a aprendizagem. Em contrapartida, a perspectiva sócio-histórico-cultural resgata os processos de transmissão e assimilação do conhecimento na relação das gerações sem cair no racionalismo da pedagogia tradicional de uma transmissibilidade independente do meio social e histórico em que se está inserido. A transmissão e assimilação, nessa perspectiva crítica, são processos sociais e históricos necessários para a aprendizagem. Elas não são exclusivas da escola, pois que desde tenra idade o bebê em sua relação com a mãe e familiares já está inserido num ambiente social de contínua transmissão de informações - gestos, palavras, tatos etc. - que vão sendo assimilados pelo seu cérebro no qual se desenvolvem as condições intra e interceptivas 
necessárias para seu desenvolvimento psíquico e humano. Portanto, uma implicação pedagógica para a aprendizagem das pessoas jovens e adultas da EJA é que a transmissão de saberes estanques da realidade (pedagogia tradicional) em nada contribuem com o desenvolvimento de seus processos de aprendizagem. Pelo contrário, tratam-se de processos mecânicos e autocráticos que inibem aspectos fundamentais da aprendizagem como a atenção, concentração, percepção, análise, síntese etc. De outro modo, se os conhecimentos escolares se vinculam à realidade histórica e social desses sujeitos, ou seja, se a eles forem transmitidos de maneira significativa, os processos de assimilação tendem a se tornarem mais concretos, fazendo com que as funções psíquicas superiores trabalhem decididamente na apreensão dos conhecimentos e na criação de outros, novos, na relação interior e social destes com o conhecimento escolar.

Por fim, outra grande contribuição é a demonstração de que o desenvolvimento psíquico humano, de sua personalidade e consciência, são decorrentes dos processos de aprendizagem vivenciados pelo meio social em que se está inserido, e não o contrário, como defende a psicologia genética. Isso diminui o peso teórico que foi dado à noção de estágios ou etapas de desenvolvimento que acabaram por privilegiar a infância como o momento adequado da aprendizagem. Wallon, por exemplo, não ignorou a ideia de etapas, porém, não teorizou sobre elas de forma estática ou dissociada do meio social em que está inserida a criança. Pelo contrário, demonstrou como a influência do meio é fundamental para o desenvolvimento das etapas, ou seja, se o ser humano fosse abandonado a viver solitário jamais se tornaria humano. Isso tem valor significativo para pensarmos a aprendizagem de pessoas jovens e adultas da EJA, pois se os níveis de desenvolvimento psíquico e de suas funções superiores - atenção, percepção, memória, cognição, consciência etc. - podem ser prejudicados por vivências de ausência da escola no período da infância ou mesmo vivências com um meio social de condições degradantes, o oposto também pode ser considerado verdadeiro, isto é, a inserção em vivências sociais qualitativas e a processos de aprendizagem significativamente associados ao meio social e cultural desses sujeitos, certamente, promoverão o desenvolvimento daquelas funções psíquicas que tenham sido prejudicadas.

\section{CONSIDERAÇÕES FINAIS}


Como foi dito no início deste ensaio, esta é uma reflexão teórica embrionária baseada nas psicologias e pedagogias de perspectiva sócio-histórico-cultural, a partir das quais procuramos compreender as possíveis relações que seus principais elementos teóricos poderiam estabelecer com o tema da aprendizagem de pessoas jovens e adultas da modalidade de Educação de Jovens e Adultos.

Esta reflexão foi motivada pela tentativa de contrapor-se a inúmeros preconceitos e estereótipos que margeiam a Educação de Jovens e Adultos, em particular, aqueles relacionados às questões da aprendizagem que estigmatizam esses sujeitos como indoutos, rudes e incapazes de aprender em níveis mais abstratos do conhecimento científico. Entretanto, se de um lado, nossa herança pedagógica tradicional é embasada em psicologias que defenderam a infância como o momento privilegiado para o desenvolvimento dos processos de aprendizagem, de outro, as teorias sócio-histórico-culturais apresentam novas noções e possibilidades para a compreensão do fenômeno da aprendizagem, como a noção da influência do meio social e histórico para a constituição do desenvolvimento psíquico e da personalidade humanos, sem se delimitar exclusivamente à infância, o que nos permite pensar suas implicações para pessoas jovens e adultas pouco ou não escolarizadas.

Tendo em vista a condição reflexiva e teórica deste ensaio, não seria possível apresentar dados empíricos que corroborassem nossa premissa principal, de que as pessoas jovens e adultas, pouco ou não escolarizadas, são capazes de aprender à medida que se pensem métodos e práticas pedagógicas que compreendam a importância de suas vivências sociais e dos instrumentos de trabalho que podem promover seu desenvolvimento contínuo. Priorizamos refletir a aprendizagem desses sujeitos nessa perspectiva crítica. Com isso, queremos afirmar que esta reflexão pode ser desenvolvida por outras pesquisas que investigam, por exemplo, empiricamente, a aprendizagem dos sujeitos da EJA; que procurem levantar experiências de aprendizagens bem-sucedidas e relacionar os fatores que contribuíram para o sucesso desses sujeitos.

Esperamos que esta reflexão provoque em seus leitores, especialmente nos docentes envolvidos com a Educação de Jovens e Adultos que todos os dias enfrentam juntamente com seus educandos e educandas os desafios do processo de ensino e aprendizagem, a desmistificação de fetiches que estigmatizam os sujeitos da EJA e a própria modalidade, como se fossem inferiores em comparação com as demais, como se estivessem recebendo um favor do Estado brasileiro ao invés do cumprimento de um direito social que lhes foi 
garantido pela Constituição. Uma pedagogia para a EJA passa pela compreensão da aprendizagem desses educandos e educandas como qualitativamente possível a partir de sua realidade concreta e objetiva. Isso significa que o trabalho pedagógico tradicional que toma esses educandos e educandas como sujeitos passivos diante de um professor ativo que detém determinado conhecimento - o conteúdo - que será transmitido mecanicamente aos alunos e alunas tende ao insucesso, pois sua desconexão com o mundo real e concreto dos sujeitos é um obstáculo à aprendizagem.

\section{REFERÊNCIAS}

BARBOSA, I. G. Psicologia sócio-histórico-cultural e pedagogia sócio-histórico-cultural: contribuições para o repensar das teorias pedagógicas e suas concepções de consciência. 1991. Dissertação (Mestrado em educação escolar brasileira) - Faculdade de Educação, Universidade Federal de Goiás, Goiânia, 1991.

BRASIL. Ministério da Educação. Parecer CNE/CEB n 11, de 20 de maio de 2000. Institui as diretrizes curriculares nacionais para a Educação de Jovens e Adultos. Brasília: MEC, 2000 .

IVIC, I. Lev Semionovich Vigotski. Trad. José Eustáquio Romão. Recife: Fundação Joaquim Nabuco, Editora Massangana, 2010. (Coleção Educadores MEC)

LEMME, P. Memórias de um educador. 2. ed. Brasília, DF: Inep, 2004. 5 v.

LEONTIEV, A. N. O homem e a cultura. In: LEONTIEV, A. N. O desenvolvimento do psiquismo. Trad. Manuel Dias Duarte. Lisboa, Portugal: Horizonte Universitário, 1978. p. 259-284.

LURIA, A. R. Curso de psicologia geral: introdução evolucionista à psicologia. Trad. Paulo Bezerra. 2. ed. Rio de Janeiro: Civilização Brasileira, 1991. v. 1.

PAIVA, V. História da educação popular no Brasil: educação popular e educação de adultos. 6. ed. São Paulo: Loyola, 2003.

VIGOTSKI, L. S. A brincadeira e o seu papel no desenvolvimento psíquico da criança. Trad. Zoia Prestes. Revista Virtual de Gestão de Iniciativas Sociais, n. 8, p. 23-36, abril de 2007.

VIGOTSKI, L. S. A formação social da mente: o desenvolvimento dos processos psicológicos superiores. Trad. José Cipolla Neto e outros. São Paulo: Martins Fontes, 2008.

VIGOTSKI, L. S. Quarta aula: a questão do meio na pedologia. Tradução Márcia Pileggi Vinha. Revista USP, São Paulo, 2010, 21(4), 681-701.

WALLON, H. As origens do caráter na criança: os prelúdios do sentimento de personalidade. Trad. Pedro da Silva Dantas. São Paulo: Difusão Europeia do Livro, 1971. 
WALLON, H. Psicologia e educação da infância. Trad. Ana Rabaça. Lisboa, Portugal: Estampa, 1975. 